\title{
ALTERNATIVE ENERGY: MODELLING RESOURCE CONFLICT WITHIN AN ENERGY ENVIRONMENT
}

\author{
Peter Baur* \\ University of Johannesburg \\ peterb@uj.ac.za
}

October 2011

\begin{abstract}
With growing infrastructural pressure induced by urban densification combined with rural development and the increasing demands of industrialisation, South Africa is facing two related challenges. The first is a lack of sufficient energy to satisfactorily fulfil the needs of the expanding economy. The second is that South Africa has limited access to water.

Electricity generation using the traditional coal-burning power stations requires vast amounts of water, for amongst other things, steam generation to drive the turbines and water is also used in the cooling process. Thus, as the demand for electricity grows, so too does the pressure on the country's strained water supplies.

The growing demand for electricity favours the building of new traditional coal- burning power stations, which emit vast amounts of pollutants into the atmosphere, negatively affecting the environment. This leads to a degree of conflict between stakeholders, namely the energy producers, government bodies, and environmentalists.

This paper uses Hirshleifer's Conflict Success Function to highlight the 'urgency' of replacing traditional fuel-based power stations with alternative renewable energy generators, using South Africa as a case study.
\end{abstract}

Keywords

Alternative Energy, Hirshleifer, Non-Renewable Resources, Clean Energy, Conflict-Economics, Environment.

*Dr Peter Baur is a senior lecturer at the Department of Economics and Econometrics, Universit of Johannesburg, South Africa. 


\section{BACKGROUND}

In the past environmentalists have warned about food shortages, growth in pollution, climate change and the depletion of global fuel stocks. However, the focus has shifted to one of serious regional water shortages in many countries, to the point that at some stage, in the not too distant future, conflict may arise over water (Meyer, 2007). The decision to protect our natural water resources becomes a question of political opinion and the general head-butting of policy makers. The argument for protecting our water resources overlaps with the need to provide cheap electricity for a growing economy. The generation of cheap electricity taps into available fresh water supplies, so the decision whether to conserve water resources or produce cheap energy becomes an argument with a political agenda.

Given the huge deficiencies mentioned surrounding the issues of political or social agendas, Corfee-Morlot, Maslin and Burgess (2007) argue strongly that the interactions within the sciences, especially between the environmental and the social opinions are somewhat conflicting due in part to the social and political opinion. Cultural and social values are often opposed to the concerns of biology and nature, and nature is often seen as a constraint to society.

Furthermore, beyond the spectrum of policy agenda and its related issues, there is still the problem of appropriate data and suitable statistical analysis. This is why, according to Freedman, Rothenburg and Sutch (1983), energy models cannot be relied upon in forecasting or policy analysis. The models are often built on poor data and uncertainty and, therefore, there is scepticism around the logic associated with these models. The arguments around the energy models thus become subjective and forecasts based on these models are at best, questionable and at worst, less than credible.

Weyant (1985) and Murphy and Shaw (1995) noted that there is little agreement among the model builders, primarily because of the differences in issues addressed by the models, which have resulted in false images being projected. This seen predominantly through political ideologies and also in the dynamics associated with the choice of the data.

This paper will use Hirshleifer's Conflict Success Function (CSF) to help filter out the disagreements between the policy-makers, so as to highlight the need to protect our limited water supplies by producing alternate energy. Hirshleifer's Conflict Success Function is the building block for introducing appropriation possibilities into economic models where there is potential or apparent conflict. This conflict model appears to perform best when an interdependence exists between economic and other related variables, and when there is an appropriation of the resources so that there is a loser and winner (Anderton \& Carter, 2009:246).

The Hirshleifer's Conflict Success Function does not just consider a unilateral conflict, but examines and models the conflict through many functional layers that are restricted with specific assumptions providing a multilateral perspective. Neither side is ever going to be an equal contestant and thus this model has the added benefit of modelling a scenario and then applying subjective variables to determine an outcome or propose a scenario for a real-world interpretation as tested in the model. 


\section{ELECTRICITY PRODUCTION AND WATER CONSUMPTION}

The way in which energy is produced, using cheap renewable resources, is often debated through a complex mesh of international ideologies and political views (International Energy Forum, 2010). It is indisputable that energy is crucial for economic and social development. Therefore, energy is often an important consideration in developing political relations between countries.

Energy production from fossil fuels negatively affects the global ecological environment through the emission of carbon and the consumption of water. This is especially the case in South Africa, with our limited the water supplies. This argument can be extended to the pollution of the very sensitive aqueous environment. Chadwick, Highton and Palmer (1985) suggest that the exploitation and utilisation of coal in the past has left a very sad legacy of environmental and health problems, especially in developing regions. Furthermore, Sovacool (2007) argues that there are additional side effects of using coal-based power stations leading to increasing levels of carbon dioxide in the atmosphere, which is considered to be the greatest contributor to greenhouse gas and, ultimately, a driving factor of environmental change and global warming.

In the United States, the Electricity Utilities was responsible for $72 \%$ of sulphur dioxide emissions, $40 \%$ of nitrogen oxide emissions, and about 59 million tons of carbon dioxide emissions. The problems around the use of coal were not related only to air pollution. They could be extended to the impact that energy production has on the water environment. Clearly, environmental degradation through the multiplier process continues to have an impact at many levels causing considerable environmental stress (Chadwick, Highton, \& Palmer, 1985).

South Africa's prime energy producer, Eskom, contributes approximately $95 \%$ of the total energy supply for the country of which $88 \%$ is coal-based. As per the mandate of Eskom (Moosa, 2007), and due to the abundant coal supplies that exist within the country, it is argued that the continued production of energy using coal-based power stations could ultimately help to alleviate the social demand for cheap energy (Friedman, 2010). Total production of electricity in South Africa has doubled from approximately 124000 gigawatt hours in the mid-1980s to approximately 241000 gigawatt hours by late 2009 (Quantec, 2010).

However, the increase in energy produced may not be sufficient to actually achieving the appropriate development objectives of a growing emerging economy. This is apparent through Whites Law, which Duncan (2001) introduces as the overall relationship between population growth and the growth of energy production. 'Other factors remaining constant, culture evolves as the amount of energy harnessed per capita per year is increased or as the efficiency of the instrumental means of putting the energy to work is increased ...' (Duncan, 2001:503). When mapping this relationship in South Africa, the relative 'flatness' of the trend highlighted by running a four-year moving average, highlighted in FIGURE 1, could indicate that the current energy production for South Africa is barely in line with growing population requirements. 


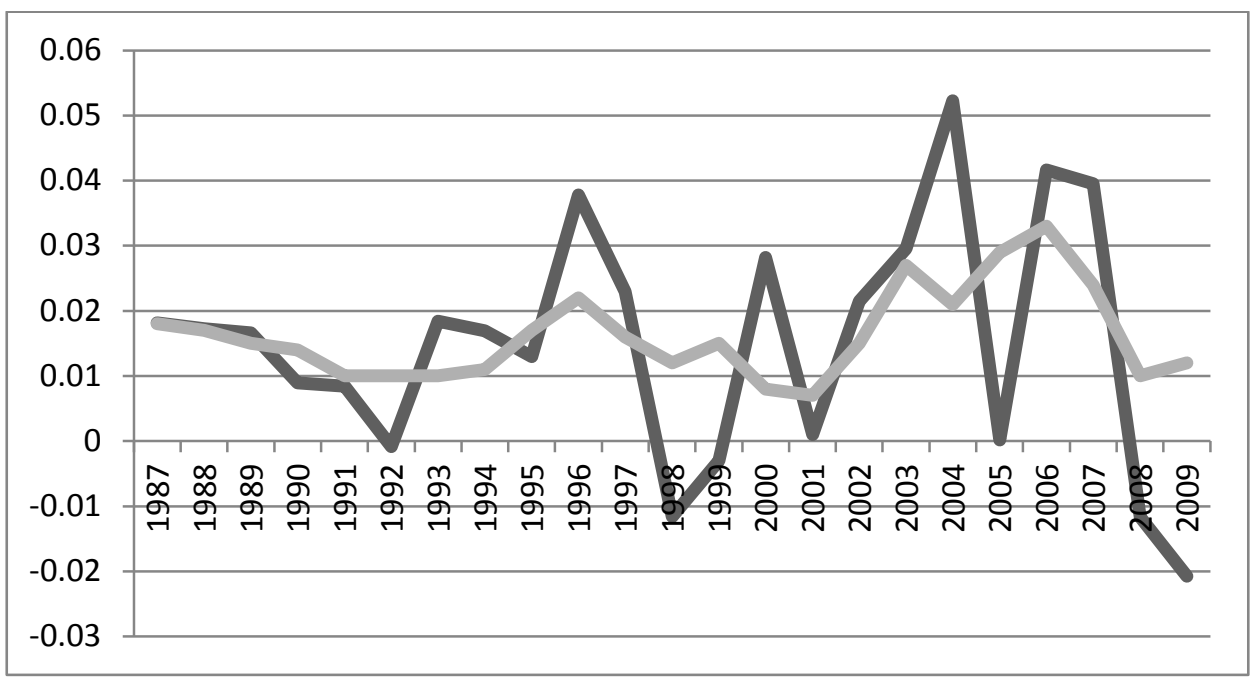

FIGURE 1: Graphically depicting White's Law for the energy produced in South Africa, the dashed line using year on year data, and the solid line using a four-year moving average between 1987 and 2009

\section{Source: Data derived from World Bank (1987-2009)}

A problem could arise because the trend in global electricity demand is most likely to double between 2005 and 2030 (Chu, 2010). This could be a problem for South Africa, as a large increase in the predicted demand for electricity will also put pressure on the demand for water used in energy production. This is compounded by an overall increase in the global population and an overall average increase in global living standards translating into an increase in demand for water. It is estimated that the global demand for water doubles approximately every 20 years (Meyer, 2007).

Unfortunately, fresh usable water is not distributed uniformly across regions (Meyer, 2007), and the rainfall levels for South Africa are somewhat constrained to very limited annual amounts (Aquastat, 2010). This may be negatively affected by long-lasting droughts, \&l Niño, La Niña and some climate variation (Meyer, 2007). Ironically, the issue of global warming, climate change, and the effect that this has on rainfall and water supply, has only gained public attention and become a political priority over the last decade (Corfee-Morlot, Maslin, \& Burgess, 2007).

Based on a low average rainfall and a limited supply of renewable fresh water, South Africa, in particular, is experiencing critical water shortages. In a report issued by the Department of Water Affairs and Forestry (DWAF) in 1997, it was recognised that South Africa faced potentially disastrous consequences in terms of available fresh water for human consumption if serious changes were not made in the use and management of the very limited fresh water supplies. Appropriate measures should thus be taken to prevent the stagnation of socio-economic development in South Africa due to the lack of sufficient drinking water (Eberhardt \& Pegram, 2000).

The amount of water readily available for consumption in South Africa (in the form of fresh water streams and rivers) only amounts to only about $0.000001 \%$ of the global total water supply (Duca \& Fuscoe, 1966). At the same time, approximately $40 \%$ of the world's population 
live in areas that are considered to be 'water stressed'. By 2025 the number of people living in water-stressed areas will have grown to approximately $50 \%$ of the global population. (International Energy Forum, 2010) In other words, more people are seeking access to smaller supplies of usable water.

With this in mind, it is often cited that the lack of access to clean water continues to be the leading cause of illness and death in much of the developing world (Ravenga, Brunner, Henninger, Kassem, \& Payne, 2000) and the global primary water supplies will have to be increased by $22.5 \%$ to meet the minimum fresh water demand over the next decade (Kumar, 2003). The amount of available fresh water within South Africa is insufficient to meet the projected demands at current usage within the next 30 years or so. (Eberhardt \& Pegram, 2000:2)

The problem with most coal-driven power stations, given the constraint of available fresh water, is that, on average, coal stations require between 530 to 2100 litres of water per 1000 kilowatt hours of electricity produced (Jones, 2003). The amount of water consumed can also depend on extreme weather events, altitude, climate, and other environmental variables which severely affect the performance of wet-cooled power stations. (Moosa, 2007).

Eberhardt and Pegram, (2000) and Friedman (2010) argue their concern is around building coalbased powers stations in countries that are water scarce, as opposed to finding alternative means of producing energy that are not coal- (or nuclear-) driven and do not require vast amounts of water in the production of electricity. Furthermore, Sovacool (2007) argues that renewable energy systems such as generators that create energy from sunlight, falling water, biomass, waste and geothermal sources, appear to offer better returns than the non-renewable types based on a case study done in the United States.. In this study it was estimated that the fossil fuel and nuclear power plants are the second largest consumer of fresh water. The United States consumes about 48.2 trillion gallons of water per annum. This is not just to generate steam to drive the turbines. Water is also used in the cooling and moving of sludge. Once the sludge comes in contact with water, its toxins render the water useless and, in many cases, simply dangerous. This also negatively affects the aquatic environment. Along with this, the sludge waste has to be dealt with, and environmental run-off is a major concern to most environmentalists (Sovacool, 2007).

However, this argument introduced by Sovacool in the United States is not standalone and onesided. The reality of choosing renewable energy over non-renewable energy production methods needs to take into account issues such as available technology, economies of scale, and social pressures that may be more pronounced in the United States of America as opposed to many of the developing countries. This too is subject to social opinion.

The urgency of finding an alternative to coal-based energy production can be expressed by using Hirshleifer's Military Model of Conflict.

\section{INTRODUCING HIRSHLEIFER'S MODEL OF CONFLICT}

\subsection{Defining an area of conflict}

The conflict between water for consumption and water for energy production is often overlooked. Water and energy are both necessary for development. Yet, energy production uses water and takes available water away from households. On the one hand, it is necessary to argue for affordable energy, which is very important in order to achieve the overall goals of 
development. On the other hand, there is the potential for the misuse or overall exploitation of water that may actually have far-reaching negative consequences for both the environment and for communities within regions or even across regions.

In order to preserve fresh water reserves and to protect the global ecosystem, alternative energy production should be considered. Costs associated with energy production fall outside of the scope of this paper. It should be assumed that the costs associated with developing and implementing alternative energy production may be higher in the early stages because of economies of scale and the implementation costs associated with new modern technology. However, it is suggested that, in the long run, the overall cost of using non-renewable energy to the environment, through poor policy implementation, could be far greater.

\subsection{The conflict success function}

The 'conflict' examined in this paper will be modelled within South Africa between the energy producer and the environmentalist. So, on the one hand there is the local energy utility that currently produces energy using coal-based technology. On the other hand there is the 'environmentalist', who is, collectively speaking, seeking to shift policy towards producing energy through alternative means. The term here for the 'environmentalist' may not necessarily be more efficient. The environmentalist here is assumed to be arguing for alternative means of producing energy and encouraging policy which is leaning towards a state of energy production that is not dependant on using fresh water stocks in the production of energy.

The Conflict Success Function (CSF) introduced by Hirshleifer in 1995, models how the 'fighting' efforts of players combine to determine the distribution of a contested resource (Anderton \& Carter, 2009). In this paper, the contested resource will be the very limited supply of water. The conflict success measures the proportion of the available 'fresh water' controlled by either the energy producer or by the environmentalist. In an extreme case, either the energy producer or the environmentalist could control the entire available water supply in a winner-takes-it-all contest. The CSF can be examined from two perspectives, i.e. from the perspective of the ratio form where we assume rational players and a perfect distribution of information. Later, the logistic form of this model will be examined, and within the logistics form of the model, information is restricted.

\subsubsection{The conflict success function as presented in the ratio form}

Under the ratio form of this model, the conflict success depends on the ratio of the attitudes of the role players: $\mathrm{Ma} / \mathrm{Mb}$. This is applied under ideal economic conditions in which you would find that all the players are rational (have access to full information) and they show continuing efforts without need for rest or delays (Anderton \& Carter, 2009:247) See FIGURE 2, where Z = $m=$ 1 .

The CSF function in the ratio form is as follows.

$$
p a=\left(\frac{(M a)^{m}}{\left((M a)^{m}\right)+((Z)(M b))^{m}}\right) \text { and } p b=\left(\frac{((Z)(M b))^{m}}{\left((M a)^{m}\right)+((Z)(M b))^{m}}\right)
$$

Drawing from Hirshleifer 1995 model, $p a$ represents the conflict success of the environmentalist and $p b$ represents the conflict success of the energy producer. For the purpose of this research, the assumption has been that both parties are equally efficient in transferring their input 
strategies into conflict effort. This could mean that if the environmentalists invent a new strategy to challenge the energy producer, then that strategy could be completely effective in that the energy producer is totally influenced by the strategy adopted by the environmentalist. This could also then also be true for the energy producer who may apply a new or similar strategy in reverse. $Z$ is thus equal to $m$ and both $Z$ and $m$ are equal to 1 . However, this does not mean that both parties will apply the same strategies.

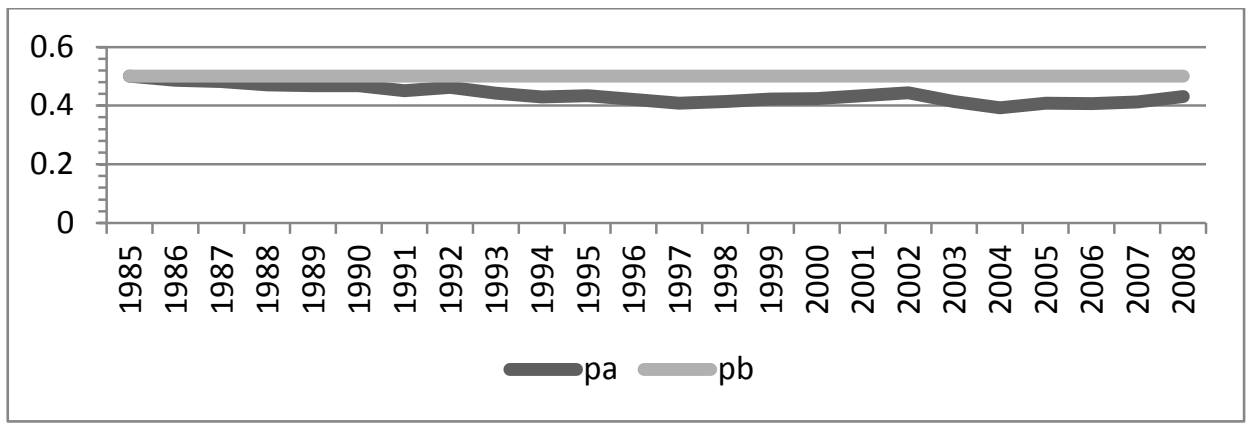

FIGURE 2: Ratio form of the conflict success function from 1985 to 2008, using 1985 as the base year

\section{Source: Author's calculations}

FIGURE 2 shows the success of the respective parties, namely the environmentalist $p a$, and the energy producer $p b$. Plotting the respective data from 1985 as the base year of this study, the fighting efforts of the 'environmentalist' are shown to be insufficient to meet the challenge of the energy producers (see TABLE 1 in the appendix). This could imply that, in the case of South Africa, energy policy dominates over the availability of fresh water. This is supported by Smith (2005), who argues that within South Africa a great difficulty exists in trying to balance costrecovery imperatives with the constitutional requirements to extend equity to previously disenfranchised households (Smith, 2005:159-169).

In interpreting this data, the model paints a picture of an energy producer who does provide energy to meet the challenges of sustainable development but, at the cost of neglecting the environment through the impact on fresh water requirements, is interpreted as a loss by the environmentalist.

\subsubsection{The conflict success function in the Logistics form}

Hirshleifer's Conflict Success Function can also be represented in the logistics form, as follows.

$$
p a=\frac{1}{1+\exp (m((Z M b)-M a))} \text { and } p b=\frac{1}{1+\exp (m((M a-(Z M b))))}
$$

Again, as in the ratio form of this model, $p a$ represents the conflict success of the environmentalist and $p b$ represents the conflict success of the energy producer. Under the logistics form of this model, the conflict success depends on the difference in the strategies applied by the role players: $M a-M b$, which is applied under non-ideal economic conditions where you would expect that the players are not acting in a purely rational manner, and have 
only partial or limited information available to each of them (Anderton \& Carter, 2009:247). See FIGURE 3 and once again $Z=m=1$.

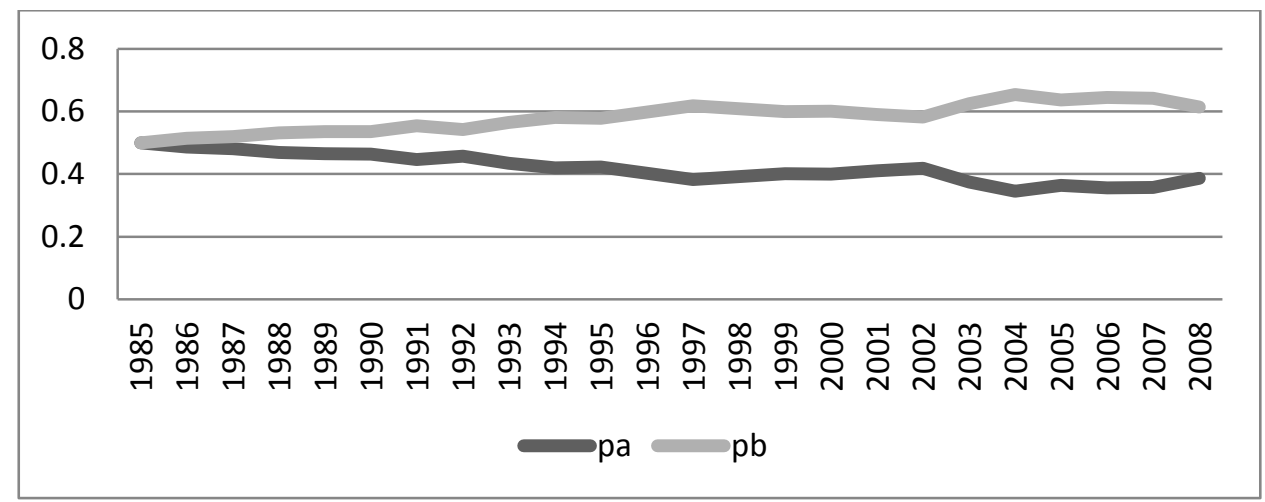

FIGURE 3: Logistics form of the Conflict Success Function from 1985 to 2008, using 1985 as the base year

Source: Author's calculations

As in FIGURE 2, FIGURE 3 shows the success functions of the environmentalist $p a$, and the energy producer $p b$. Plotting the respective data, the fighting efforts of the 'environmentalist' are shown not only to be insufficient to meet the challenge of the energy producers, but now the energy policy of the government appears to be dominant over the 'environmentalist'. Where there is a loss for one player, there is a gain for the other and this is reflected in the graphical representation of the data highlighted by the mirror image of the data of the two players (see TABLE 2 in the appendix).

An interpretation of the logistics form of this model highlights how the 'energy producer' is gaining at a cost to the 'environmentalist'. However, it is insufficient just to claim that the 'environmentalist' is losing to the 'energy producer'. The question is, when using the reaction function of this model, can this model suitably demonstrate how much additional effort would be required by the 'environmentalist' to hold on to the remaining available water stocks?

\subsection{Reaction function somewhat towards equilibrium}

The reaction function as presented by Anderton and Carter (2009) shows the level of effort required by the 'environmentalist', given the level of effort that is pursued by the 'energy producer', in order to achieve a balance of resources between the two players (Anderton \& Carter, 2009:251). In other words, this function can indicate how much additional effort the 'environmentalist' needs to apply to the policy to be able to compete with the 'energy producer' in order to achieve some form of policy equity. In this case, how much 'more' effort is required by the 'environmentalist' to hold onto the water reserves that have been alternatively used by the 'energy producer'. This is given in the following function:

$$
M A=\sqrt{(Z M b R(1-\delta))}-(Z \delta) \text { and } M B=\left(\left(\frac{1}{Z}\right)(\sqrt{Z M a R(1-\delta)}-(M a))\right)
$$


FIGURE 4 plots the reaction function for the conflicting groups, namely the 'environmentalist' denoted by $M a^{\star}$ and the 'energy producer', denoted by $M b^{*}$. See data in TABLE 3 in the appendix. From this graph it is evident that the 'environmentalist' requires a lot more 'effort' in order to be equal to or exceed the activity of the 'energy producer'. This additional effort could be in any specific form, from public awareness and political lobbing strategies, to acquisitioning funds that could be used to develop and implement alternative energy programmes.

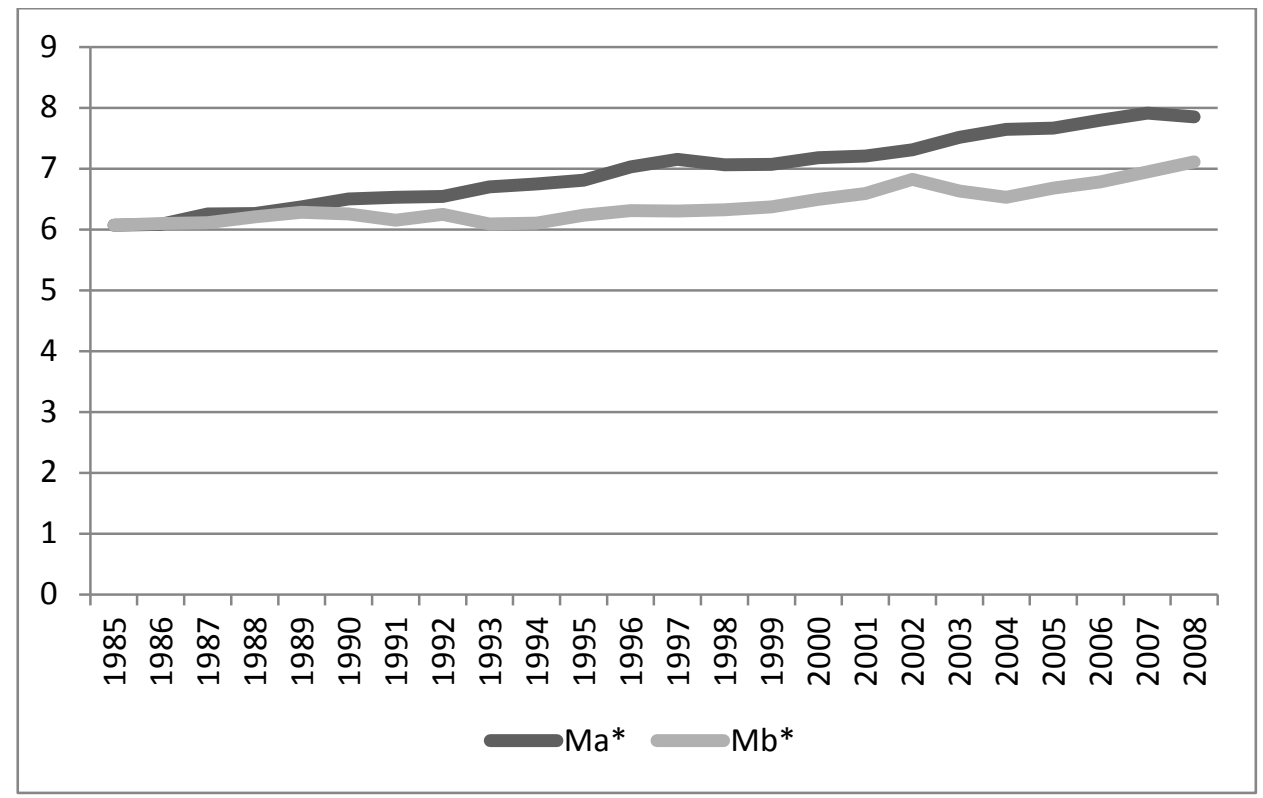

FIGURE 4: Plotting the reaction function from 1985 to 2008, using 1985 as the base year

\section{Source: Author'scalculations}

This finding is strongly supported by the work of Sovacool (2007) who concludes from his own study that it makes sound sense to invest in alternative energy programmes. These programmes may be a lot smaller than the monolith coal or nuclear generators, but over time, with the expansion of alternative energy, long-term benefits will be achieved, and become clearly visible in the social and ecological environments (Sovacool, 2007).

Coming back to the model of resource conflict, it was proposed that water is the conflicting resource that is disputed between two very important policy objectives. On the one hand, water is required in the cooling process of creating energy, which in turn is required for economic growth. On the other hand, the use of water for energy conflicts with social and ecological concerns by removing water from the available fresh water supply required by a growing population. Thus, we have two policies, which have very conflicting outcomes, while simultaneously both policies support the objectives of development in one way or another. In order to analyse this conflict, a model of 'Resource Conflict' maps out the conflict between the players chronologically. 


\subsection{Building the basic model of resource conflict}

Once again in this model of resource conflict, it is proposed that water is the conflicting resource that is disputed between the two very important policy objectives. On the one hand, water is required in the cooling process of creating energy, which in turn is required for economic growth. On the other hand, water is used by society as a basic life-sustaining necessity. The use of water for energy conflicts with the social requirements by taking water from the stockpile of available fresh water required by the growing population.

We have two policies, which have conflicting outcomes, while simultaneously both policies support the objectives of development in one way or another. The Basic Model of Resource Conflict, as proposed by Anderton and Carter (2009), lays a parameter by assuming that there are only two role players, namely the 'energy producers' and the 'environmentalists' who are in conflict with one another for a share of the fixed supply of fresh water (Anderton \& Carter, 2009:249).

By assuming that the success of the two players is going to be measured through the amount of the resource that each of the individual players can potentially control. In this model, the net supply of fresh water is the disputed resource. Fresh water controlled by the 'environmentalist' is noted in the model as NRa and the amount of fresh water controlled by the 'energy producer' is noted by $\mathrm{NRb}$. As there is conflict between the players the function will be given as the following formula.

$$
N R a=R a+\left(\frac{R(1-\delta)}{(1+Z)^{2}}\right) \text { and } N R b=R b+\frac{Z^{2} R(1-\delta)}{(1+Z)^{2}}
$$

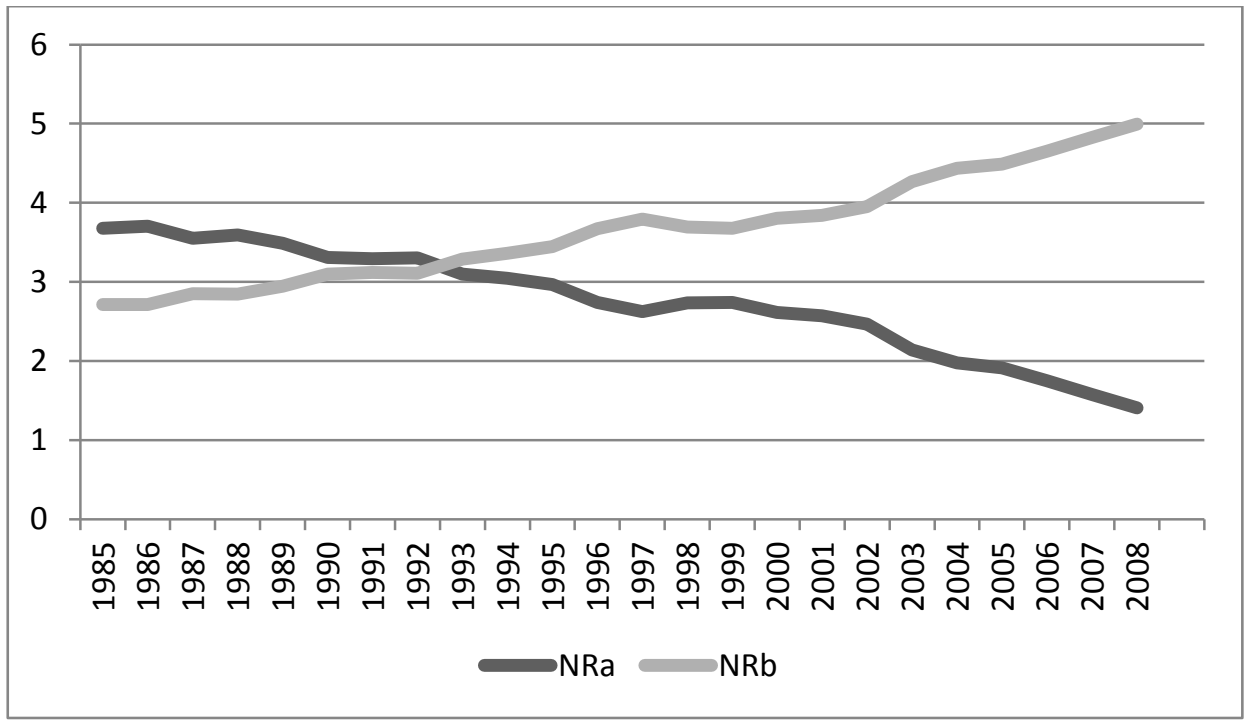

FIGURE 5: Plotting the resource holdings from 1985 to 2008 , using 1985 as a base year

Source: Author's calculations 
In FIGURE 5, the amount of fresh water that is controlled by the conflicting groups, namely the 'Environmentalist' is denoted by NRa and the 'Energy Producer' is denoted by NRb. (See data in TABLE 5 in the appendix).

From FIGURE 5, using 1985 as the base year, we can see that the 'environmentalist' has a greater share of the water supply. However, given the demand for energy, and combined with greater social pressure, the 'environmentalist' and the 'energy producer' break even between 1992 and 1993, and after 1993, the 'energy producer' takes an ever-increasing supply of the available water stock at the cost of the 'environmentalist'.

In order to test for policy response completely hypothetically, assume a scenario if electricity generation based on common water-cooled power stations was halved by replacing energy production with an alternative that is not dependent on water for cooling, such as solar, wind or wave technology. Using 1997 as the date that energy production from water-cooled power stations was halved (see FIGURE 6).

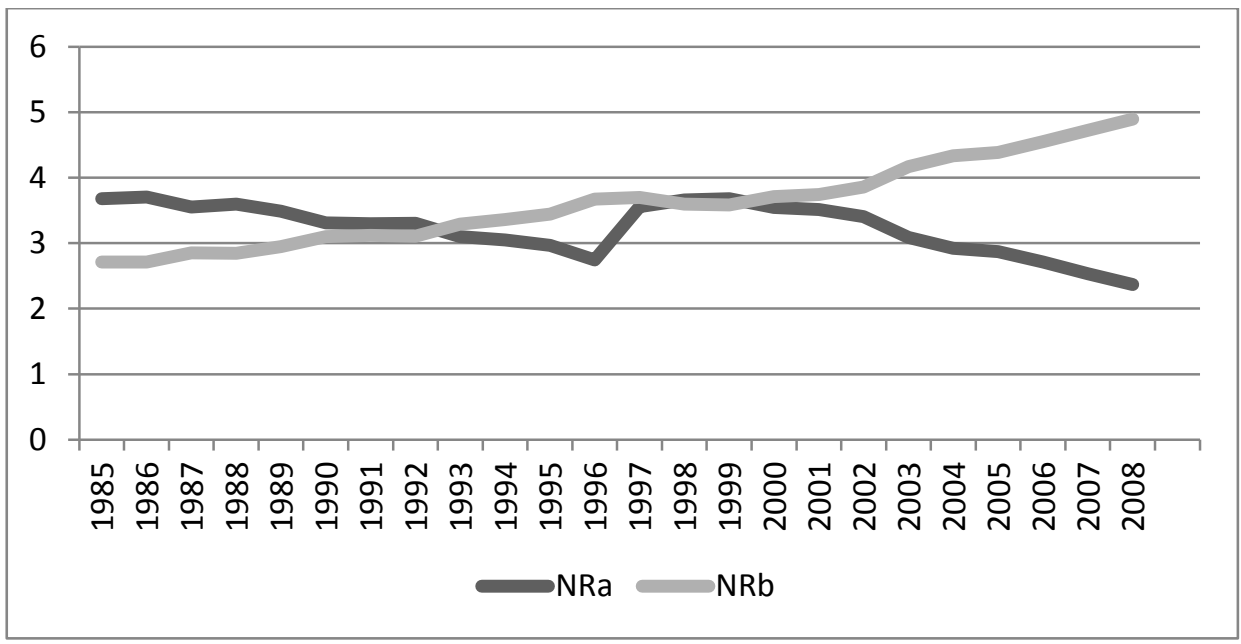

FIGURE 6: Plotting the resource conflict from 1985 to 2008, using 1985 as a base year and
simulating an energy policy shift in 1997

Source: Author's calculations

In FIGURE 6, the 'resource holdings' for the conflicting groups, namely the 'environmentalist' denoted by NRa and the 'energy producer' denoted by NRb as per the data in TABLE 6 in the appendix. What we discover by applying this model is that even if we went back in time, and halved energy production in 2007, the 'environmentalist' appears to gain in terms of their objectives by gaining their share of the water for a short time. However, after a short period of time, while the 'energy producer' may have been slightly compromised, the 'environmentalist' begins to lose ground to the 'energy producer'. Implications of this could hint towards a situation where a more radical and extreme approach to transform to alternative energy needs to be adopted.

However, climate change is also something we need to consider in this model. So by assuming a situation, where hypothetically the rainfall was to suddenly increase in 1997, which is 
demonstrated by simulating a single unit increase in available water, and plotting the results in FIGURE 7.

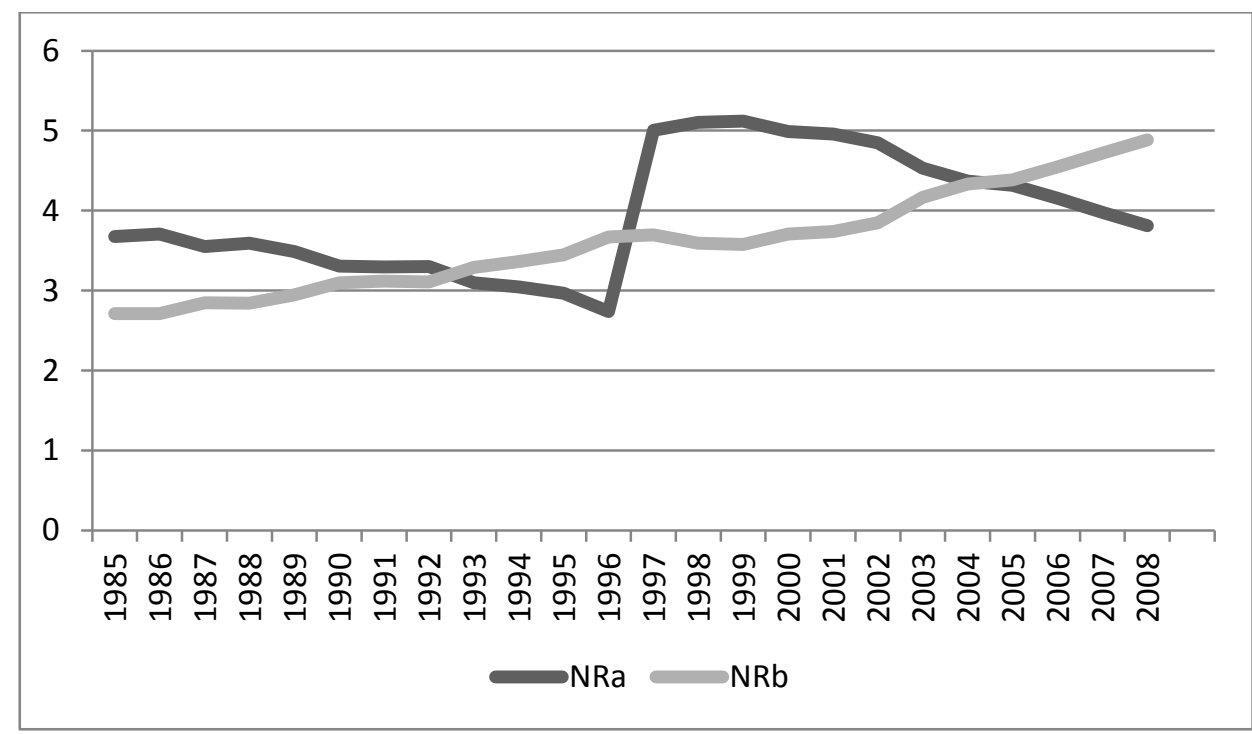

FIGURE 7: Plotting the resource conflict from 1985 to 2008, using 1985 as a base year and simulating a rainfall increase in 1997

\section{Source: Author's calculations}

In FIGURE 7, by incorporating a hypothetical simulation of an increase in rainfall into the model demonstrates how the 'environmentalist' will have achieved albeit (indirectly) positive ground. However, the growing demands of the 'energy producer' will eventually outperform the needs of the 'environmentalist'. See TABLE 6 in the abstract.

Looking at FIGURE 8, hypothetically by simulating a simultaneous rainfall increase, and simultaneously a radical switch to 'alternative' energy, both in 1997, it is noted, that as in FIGURE 7, the 'environmentalist' gains only briefly over the 'energy producer', but loses ground gradually, without any long-term recovery. See FIGURE 8 and TABL 8 in the appendix. 


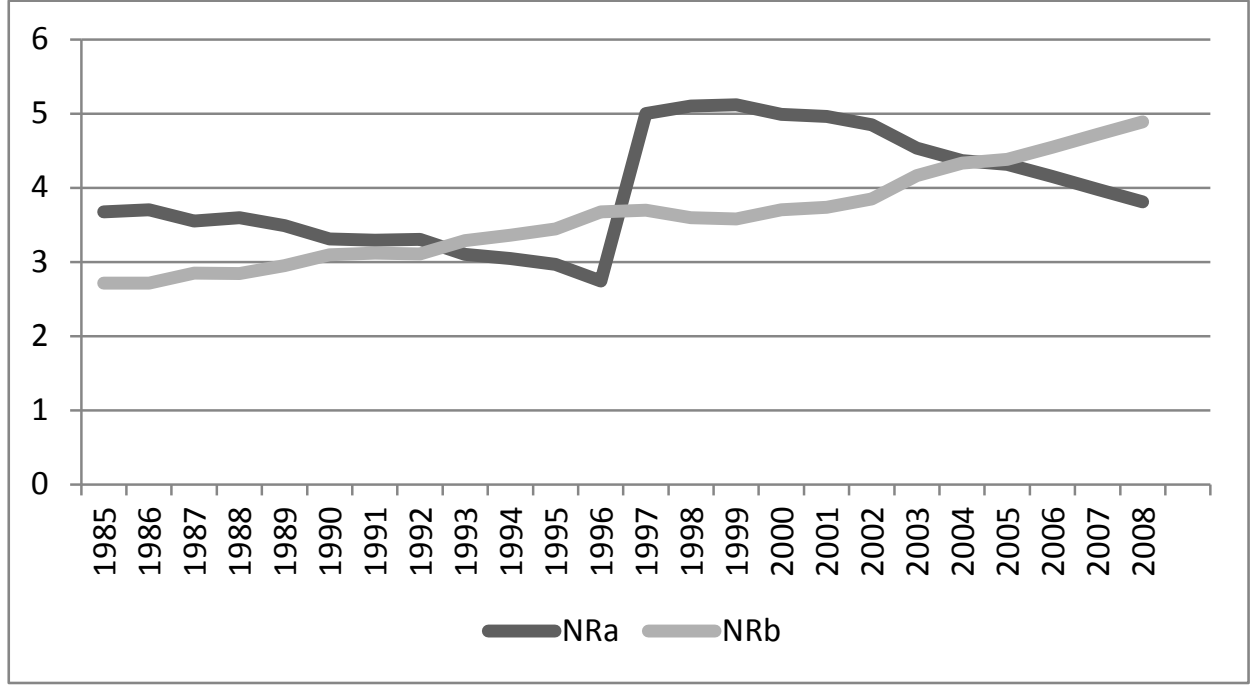

FIGURE 8: Plotting the resource conflict from 1985 to 2008, using 1985 as a base year and simulating a rainfall increase, as well as a policy shift of the 'energy producer' to alternative energy in 1997

Source: Author's calculations

After applying working data for a South African context to these models, it appears that the models are robust. Thus, it appears that the models are secure enough to test policy applied to South Africa to determine if the policy is appropriate for South Africa or not.

\section{APPLYING HIRSHLEIFER'S BASIC MODEL TO SOUTH AFRICA'S INTEGRATED RESOURCE PLAN FOR ELECTRICITY 2010-2030}

The integrated Resource Plan for Electricity (Department of Energy, 2011) proposes a policy outline for electricity production. Numerous scenarios are proposed in the final report of this resource plan. Within the plan, there are a number of scenarios proposed and presented, but most fall outside the scope of this paper. The choice was made to analyse the core 'base case' scenario as proposed in the energy plan.

The policy is analysed by applying data of the 'base case' scenario to the 'reaction function' and the 'resource holdings' function of the model. See FIGURE 9 and FIGURE 10, and TABLE 9 and TABLE 10 in the appendix. 


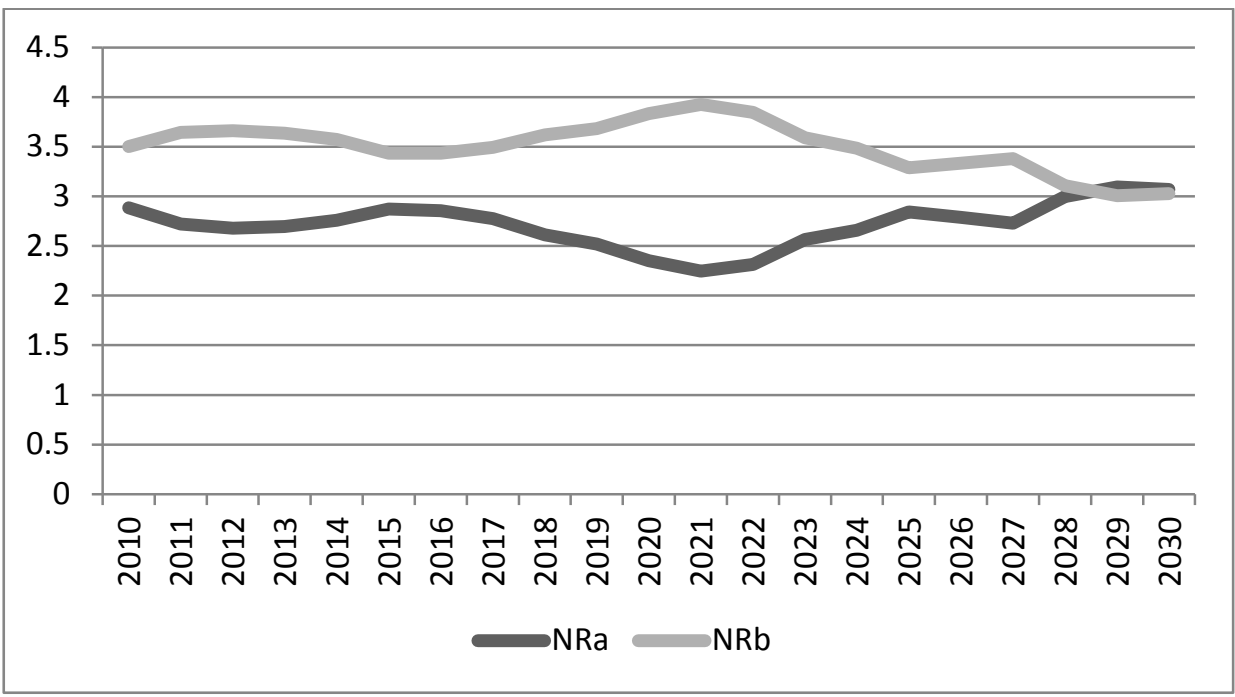

FIGURE 9: Plotting the recource holdings from 2010 to 2030, using 2010 as a base year and applying the data as per the base case scenario in the final report of the IRP 20102030. data derived from the IRP 2010-2030, final report

\section{Source: Author's calculations}

As per FIGURE 9, it becomes apparent that by using water as the measurement of the effectiveness of the policy initiated within the IRP 2010-2030, the model highlights that, even though the policy initiated within the IRP report argues for a more environmentally suitable approach to the economy, the 'environmentalist' whose objective in this study was to secure water for social related objectives, may achieve its objectives as late as 2028 or possibly even later.

This is indicated in FIGURE 9, where the resource holding of the 'energy producer' is bypassed by that of the 'environmentalist' only after 2028. In order to test if this is indeed the case, the data derived from the IRP report is applied to the 'reaction function' of this model. See FIGURE $\mathbf{1 0 .}$ 


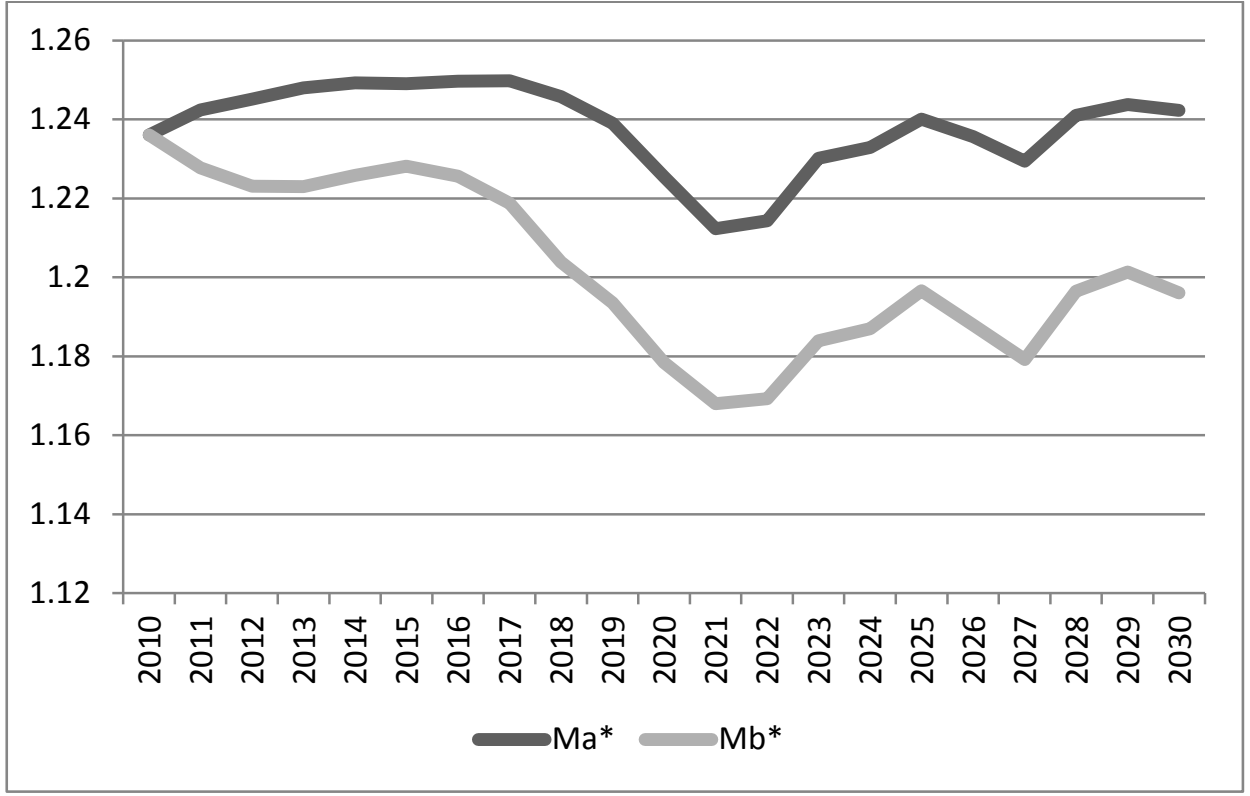

FIGURE 10: Plotting the reaction function from 2010 to 2030, using 2010 as a base year and applying the data as per the base case scenario in the final report of the IRP 20102030

Source: Author's calculations

The graphical representation in FIGURE 10, using the reaction function of Hirshleifer's Model, and applying the data released in the IRP 2010-2030 report, supports the argument that the 'environmentalist' still requires a lot more effort to achieve his goals by forcing energy production towards a more environmentally sustainable direction. This is indicated by the size of the 'gap' between the additional 'effort' of the 'environmentalist' indicated by $\mathrm{Ma}^{\star}$, as opposed to the amount of effort required by the 'energy producer' $\mathrm{Mb}$ *.

Even though the report makes provision for more alternative energy sources (Department of Energy, 2011:7-8), the sensitivity of the model argues that there is not enough done at an early enough stage. In the final draft of the Integrated Resource Plan for Electricity (IRP) 2010-2030, it was stressed that there are international calls for the reduction of carbon emissions, an increase in renewable energy, improved energy efficiency and a strong opposition to nuclear energy (Department of Energy, 2011:10).

Energy production in South Africa is driven primarily through coal-burning power stations. Due to the abundance of coalfields in South Africa, and based on growing social pressure and the related increased demand for energy, there is a trend towards building new power stations that use coal to generate electricity.

Water is an important consideration as energy production is dependent on the consumption of fresh water. South Africa's electricity utility Eskom and the African Development Bank have signed loan agreements for US\$365 million that will enable the first large-scale implementation of renewable wind and solar generation in the history of the country (I-Net Bridge, 2011). The expansion of coal-based power generation plants is a negative, and nuclear energy is not a 
suitable replacement. This point is argued by Lund (2011), that the draft IRP received criticism for its coal and nuclear expansion, its unambitious renewable energy, and its poor energy targets (Lund, 2011:15). All this supports 'White's Law' discussed earlier in this paper.

\section{FINDINGS AND DISCUSSION}

There are two primary points to highlight in the findings of this paper. The first is the role of using water as an indicator to argue for policy change. The second relates to the policy itself. Hirshleifer's Military Conflict Model, which has been used to analyse policy directed by the South African energy producer, points towards water being a very sensitive and useful test to clearly understand the urgency of selecting a suitable energy policy that may be gentler on the environment. It is not proposed that there is a need to discount carbon credits or carbon emissions and carbon analysis in any way. The study shows that water is very sensitive to measuring the effects of energy production on the environment.

There is a strong argument towards greater energy efficiency (Sovacool, 2007) from the environmentalist side. It would seem quite unreasonable, given the challenges faced by the energy producer to be responsible for supplying the rapidly increasing energy requirements. Water supply is completely dependent on climate. Many regions of the world have limited availability of water, and this seasonal. Thus, the argument of applying 'Hirshleifer's Conflict Success' model is very useful to understanding the very sensitive nature of applying appropriate policy to protect both the environment and those people that are also dependent on the environment.

\section{LIST OF REFERENCES}

Anderton, C., \& Carter, J. (2009). Principals of Conflict Economics A Primer for Social Science. New York: Cambridge University Press.

Aquastat. Food and Agriculture organization of the United Nations. (2010).Country Information. [0n Line] Available: www.fao.org/nr/water/aquastat/countries.../south_africa/index.stm. (Accessed October 2011).

Chadwick, M., Highton, N., \& Palmer, J. (1985). Developing Coal in Developing Countries. Ambio, 14(4/5), 249-252.

Chu, S. (2010). Scaling up Clean Energy. Washington DC: Clean Energy Ministerial.

Corfee-Morlot, J., Maslin, M., \& Burgess, J. (2007). Global Warming in the Public Sphere. Philosophical Transactions: Mathematical, Physical and Engineering Sciences, 365(1860), 2741-2776.

Department of Energy. (2011). Integrated Resource Plan for Electricity 2010-2030. DoE.

Duca, M. D., \& Fuscoe, J. (1966). Application of Advances in Space Technology to Water Resources Management. Water Pollution Control Federation, 38(6), 976-989.

Duncan, R. (2001). World Energy Production, Population Growth, and the Road to the Olduvai Gorge. Population and Environment, 22(5), 503-522. 
Eberhardt, R., \& Pegram, G. (2000). The Water Sector, a position paper. WWF, Macroeconomic Reforms and Sustainability Development Project. Johannesburg: DBSA, Midrand in association with the Palmer Development Group.

Freedman, D., Rothenburg, T., \& Sutch, R. (1983). On Energy Policy Models. Journal of Business \& Economic Statistics, 1(1), 24-32.

Friedman, L. (2010, June 2). New South African coal plant seeks emission credits for 'cleaner' coal function. New York Times.

I-Net Bridge. (2011, September 26). AfDB, Eskom sign $\$ 365 \mathrm{~m}$ in loan pacts. Business Report.

International Energy Forum. (2010). The Evolving Roles of International Organisations and the Private Sector in Energy Security and Sustainability. International Energy Forumn.

Jones, W. (2003, April). How Much Water Does it Take to Make Electricity. IEEE Spectrum.

Kumar, C. (2003). Fresh Water Resources: A Perspective. India: National Institute of Hydrology.

Lund, T. (2011, March). Power mad: Governmnets Tilt at an Energy Plan. FIN Week, pp. 15-18.

Meyer, W. N. (2007). The Economics of Water (First ed.). Pretoria: Van Schaik Publishers.

Moosa, V. (2007). Climate Change Information sheet. Johannesburg: Eskom.

Quantec. (2010). Electricity generation and consumption: Eskom: Electricity produced - Gigawatthours. EasyXL. Johannesburg: StatsSA, P4141. Retrieved from www.quantec.com.

Ravenga, C., Brunner, J., Henninger, N., Kassem, K., \& Payne, R. (2000). Pilot Analysis of Global Ecosystems: Wetland Ecosystems. Washington, D.C.: World Resource Institute.

Smith, L. (2005). South Africa: testing the waters of Private-Public parnerships. Amsterdam: Transnational Institute ( $\mathrm{NI})$ and Corporate Europe Observatory.

Sovacool, B. (2007). Coal and Nuclear Technologies: Creating a False Dichotomy for American Energy Policy. Policy Sciences, 4O(2), 101-122.

WorldBank. (2010). World DataBank. World Development Indicators (WDI) \& Global Development Finance (GDF). Washington DC: World Bank. [On Line] Available:

http://databank.worldbank.org/ddp/home.do. (Accessed October 2010). 


\section{APPENDIX}

Data used for South Africa to measure the Conflict Success Function in the ratio form:

As per the main literature, the CSF in the ratio form is as follows.

Where:

$$
p a=\left(\frac{(M a)^{m}}{\left((M a)^{m}\right)+((Z)(M b))^{m}}\right) \text { and } p b=\left(\frac{((Z)(M b))^{m}}{\left((M a)^{m}\right)+((Z)(M b))^{m}}\right)
$$

\section{Source: Anderson \& Carter, 2009:246-247}

- pa represents the conflict success of the 'environmentalist' derived from the CSF function proposed by Hirshleifer (1995).

- $\mathrm{pb}$ is the conflict success of the 'energy producer' as derived from the CSF function proposed by Hirshleifer (1995).

- Ma shows the growing efforts of the environmentalist. For the purpose of the paper I propose using the inverse of $\mathrm{CO}_{2}$ emissions. ( $\mathrm{kg}$ per 2000 US\$ GDP) (indexed to 1985 as the base year) Data Source: World Bank (2010). The inverse of $\mathrm{CO}_{2}$ emissions per unit GDP is very handy in that as the 'environmentalist view' becomes more dominant, it would be reflected by lower $\mathrm{CO}_{2}$ emissions per unit GDP assuming positive growth in energy output. In other words, the producers are providing cleaner energy, and the 'environmentalist' gains ground. The relationship is, therefore, positive. In the case where the concerns of the environment would be largely ignored, then the level of $\mathrm{CO}_{2}$ emissions per unit GDP would increase, and the inverse of this would be negative.

- Mb defines the effort applied by the 'energy producer'. Total energy produced by ESKOM, (Indexed to 1985 as the base year). Data Source: World Bank (2010). As the prime energy producer in South Africa, greater output of energy from ESKOM would be indicative of effort. The greater the effort made by the 'energy producer', the more electricity produced. This does not need to translate into additional power stations, this could also refer to more modern or efficient means of generating energy from the coal input. As the greatest majority of energy is produced by ESKOM, which is virtually coal dependent, the effort of the 'energy producer' should clearly translate into output.

- $m$ is a decisiveness coefficient that captures the degree to which the change or growing attitudes translate into conflict success. (e.g. if people are concerned about the environment, they may consider alternative energy. This variable is highly subjective, and as a result it needs to be kept constant and equal to $Z$.

- $Z$ is the success of the 'energy producer's' attitude towards energy production. (By producing more coal-based energy). This variable is also very subjective, and as a result needs to be kept constant and equal to $m$. By holding $Z$ constant and equal to $m$ does not need to be the rule within this model, as modifying the values for $Z$ and $m$ give varying results. As these results fall outside of the scope of this research, the variations of $m$ and $Z$ are suitable for another paper. Determining the fighting effort of the two parties concerned is highly subjective and, therefore, this model will assume both parties are equally effective in this regard. 
Baur

TABLE 1: Data used in the Conflict Success Function (CSF), Ratio Form

\begin{tabular}{|c|c|c|c|c|c|c|}
\hline Date & $p a$ & $p b$ & $m$ & $M a$ & $M b$ & Z \\
\hline 1985 & 0.5 & 0.5 & 1 & 1 & 1 & 1 \\
\hline 1986 & 0.486101 & 0.5 & 1 & 0.980106 & 1.036152 & 1 \\
\hline 1987 & 0.481481 & 0.5 & 1 & 1.006249 & 1.083655 & 1 \\
\hline 1988 & 0.470931 & 0.5 & 1 & 1.005638 & 1.129786 & 1 \\
\hline 1989 & 0.468462 & 0.5 & 1 & 1.035609 & 1.175048 & 1 \\
\hline 1990 & 0.468105 & 0.5 & 1 & 1.055821 & 1.199702 & 1 \\
\hline 1991 & 0.451419 & 0.5 & 1 & 1.006382 & 1.222992 & 1 \\
\hline 1992 & 0.462432 & 0.5 & 1 & 1.050002 & 1.220604 & 1 \\
\hline 1993 & 0.442524 & 0.5 & 1 & 1.008036 & 1.26989 & 1 \\
\hline 1994 & 0.429895 & 0.5 & 1 & 0.993153 & 1.317067 & 1 \\
\hline 1995 & 0.434301 & 0.5 & 1 & 1.039934 & 1.354569 & 1 \\
\hline 1996 & 0.421578 & 0.5 & 1 & 1.069042 & 1.466771 & 1 \\
\hline 1997 & 0.407566 & 0.5 & 1 & 1.059848 & 1.540587 & 1 \\
\hline 1998 & 0.414461 & 0.5 & 1 & 1.062782 & 1.501465 & 1 \\
\hline 1999 & 0.422511 & 0.5 & 1 & 1.091316 & 1.491611 & 1 \\
\hline 2000 & 0.424144 & 0.5 & 1 & 1.144128 & 1.553372 & 1 \\
\hline 2001 & 0.434195 & 0.5 & 1 & 1.194434 & 1.556481 & 1 \\
\hline 2002 & 0.443122 & 0.5 & 1 & 1.291859 & 1.623498 & 1 \\
\hline 2003 & 0.413279 & 0.5 & 1 & 1.216072 & 1.726427 & 1 \\
\hline 2004 & 0.392832 & 0.5 & 1 & 1.169525 & 1.80764 & 1 \\
\hline 2005 & 0.40807 & 0.5 & 1 & 1.24633 & 1.80788 & 1 \\
\hline 2006 & 0.406784 & 0.5 & 1 & 1.295054 & 1.888589 & 1 \\
\hline 2007 & 0.412264 & 0.5 & 1 & 1.375558 & 1.961033 & 1 \\
\hline 2008 & 0.431609 & 0.5 & 1 & 1.458709 & 1.920989 & 1 \\
\hline
\end{tabular}

Source: Author's calculations 
Data used for South Africa to measure the Conflict Success Function in the logistics form:

The CSF in the Logistics form is as follows.

Here the variables used remain the same as for TABLE 1.

$$
p a=\frac{1}{1+\exp (m((Z M b)-M a))} \text { and } p b=\frac{1}{1+\exp (m((M a-(Z M b))))}
$$

Source: $\quad$ Anderson \& Carter, 2009:248

TABLE 2: Data used to analyse the Conflict Success Function (CSF) in the Logistics Form

\begin{tabular}{|c|c|c|c|c|c|c|}
\hline & $p a$ & $p b$ & $m$ & $M a$ & Mb & $Z$ \\
\hline 1985 & 0.5 & 0.5 & 1 & 1 & 1 & 1 \\
\hline 1986 & 0.485992165 & 0.514008 & 1 & 0.980106 & 1.036152 & 1 \\
\hline 1987 & 0.480658218 & 0.519342 & 1 & 1.006249 & 1.083655 & 1 \\
\hline 1988 & 0.469002814 & 0.530997 & 1 & 1.005638 & 1.129786 & 1 \\
\hline 1989 & 0.465196802 & 0.534803 & 1 & 1.035609 & 1.175048 & 1 \\
\hline 1990 & 0.464091609 & 0.535908 & 1 & 1.055821 & 1.199702 & 1 \\
\hline 1991 & 0.44605812 & 0.553942 & 1 & 1.006382 & 1.222992 & 1 \\
\hline 1992 & 0.457452505 & 0.542547 & 1 & 1.050002 & 1.220604 & 1 \\
\hline 1993 & 0.434907973 & 0.565092 & 1 & 1.008036 & 1.26989 & l \\
\hline 1994 & 0.41972194 & 0.580278 & 1 & 0.993153 & 1.317067 & 1 \\
\hline 1995 & 0.42198386 & 0.578016 & 1 & 1.039934 & 1.354569 & 1 \\
\hline 1996 & 0.401858088 & 0.598142 & 1 & 1.069042 & 1.466771 & 1 \\
\hline 1997 & 0.382077704 & 0.617922 & 1 & 1.059848 & 1.540587 & 1 \\
\hline 1998 & 0.392054666 & 0.607945 & 1 & 1.062782 & 1.501465 & 1 \\
\hline 1999 & 0.40124129 & 0.598759 & 1 & 1.091316 & 1.491611 & 1 \\
\hline 2000 & 0.399093458 & 0.600907 & 1 & 1.144128 & 1.553372 & 1 \\
\hline 2001 & 0.410464205 & 0.589536 & 1 & 1.194434 & 1.556481 & 1 \\
\hline 2002 & 0.417841831 & 0.582158 & 1 & 1.291859 & 1.623498 & 1 \\
\hline 2003 & 0.375110283 & 0.62489 & 1 & 1.216072 & 1.726427 & 1 \\
\hline 2004 & 0.34567278 & 0.654327 & 1 & 1.169525 & 1.80764 & 1 \\
\hline 2005 & 0.363188865 & 0.636811 & 1 & 1.24633 & 1.80788 & 1 \\
\hline 2006 & 0.355824236 & 0.644176 & 1 & 1.295054 & 1.888589 & 1 \\
\hline 2007 & 0.357673728 & 0.642326 & 1 & 1.375558 & 1.961033 & 1 \\
\hline 2008 & 0.3864445051 & 0.613555 & 1 & 1.458709 & 1.920989 & 1 \\
\hline
\end{tabular}


Data used for South Africa to measure the Reaction Function between the Environmentalist and the Energy Producer.

The Reaction Function is as follows.

$$
M a^{*}=\sqrt{(Z M b R(1-\delta))}-(Z \delta) \text { and } M b^{*}=\left(\left(\frac{1}{Z}\right)(\sqrt{Z M a R(1-\delta)}-(M a))\right)
$$

\section{Source: Derived from Anderson \& Carter, 2009:251}

- Ma shows the growing efforts of the 'environmentalist'. For the purpose of the paper I propose using the inverse of $\mathrm{CO}_{2}$ emissions. (kg per 2000 US\$ GDP) (indexed to 1985 as the base year) Data Source: World Bank (2010).

- Mb defines the effort applied by the 'energy producer'. Total energy produced by ESKOM, (Indexed to 1985 as the base year). Data Source: World Bank (2010).

- $\boldsymbol{\delta}$ defines the proportion of loss of resources due to the conflict. As the conflict does not generate loss, or in other words, as water is not destroyed in the conflict process between the parties, it would be safe to assume that $\boldsymbol{\delta}$ is equal to zero.

- $\quad Z$ is the relative effectiveness of B's strategic effort. This is shown by the amount of electricity produced from coal as a percentage of the total energy produced within the country. This is then indexed using 1985 as base year. The effectiveness of the energy producer is determined by using the production of electricity through coal-based power stations as a percentage of the total energy produced. This then could be used as a proxy to reflect the policy used by the 'energy producer'. Source: Index data derived from data provided by the World Bank

- Rt defines the total water resource stock: total renewable fresh water, for South Africa (actual) $\left(10^{\wedge} 9 \mathrm{~m}^{3} / \mathrm{yr}\right)$ (aqua stat), and remains a constant value during the course of this analysis.

TABLE 3: Data used in the analysis of the reaction function

\begin{tabular}{llcclllll}
\hline & \multicolumn{1}{c}{$M a^{*}$} & \multicolumn{1}{c}{$M b^{*}$} & \multicolumn{1}{c}{$M a$} & \multicolumn{1}{c}{$M b$} & $\boldsymbol{\delta}$ & \multicolumn{1}{c}{$Z$} & $R t$ \\
\hline 1985 & 6.071067812 & 6.071068 & 1 & 1 & 0 & 1 & 50 \\
1986 & 6.082688231 & 6.098598 & 0.980106 & 1.036152 & 0 & 0.969539 & 50 \\
1987 & 6.25094428 & 6.112679 & 1.006249 & 1.083655 & 0 & 0.989911 & 50 \\
1988 & 6.260129132 & 6.208858 & 1.005638 & 1.129786 & 0 & 0.952864 & 50 \\
1989 & 6.368463727 & 6.278971 & 1.035609 & 1.175048 & 0 & 0.955026 & 50 \\
1990 & 6.503509995 & 6.250401 & 1.055821 & 1.199702 & 0 & 0.984452 & 50 \\
1991 & 6.529482939 & 6.15135 & 1.006382 & 1.222992 & 0 & 0.975163 & 50 \\
1992 & 6.540748323 & 6.244656 & 1.050002 & 1.220604 & 0 & 0.981202 & 50 \\
1993 & 6.697267167 & 6.092499 & 1.008036 & 1.26989 & 0 & 0.999563 & 50 \\
1994 & 6.7436822 & 6.104043 & 0.993153 & 1.317067 & 0 & 0.980345 & 50 \\
1995 & 6.807661093 & 6.234102 & 1.039934 & 1.354569 & 0 & 0.975768 & 50 \\
1996 & 7.026892697 & 6.306915 & 1.069042 & 1.466771 & 0 & 0.975323 & 50
\end{tabular}




\begin{tabular}{lccccccc}
\hline & \multicolumn{1}{c}{$M a^{*}$} & \multicolumn{1}{c}{$M b^{*}$} & \multicolumn{1}{c}{$M a$} & $M b$ & $\boldsymbol{\delta}$ & \multicolumn{1}{c}{$Z$} & $R t$ \\
\hline 1997 & 7.147738143 & 6.300404 & 1.059848 & 1.540587 & 0 & 0.969356 & 50 \\
1998 & 7.062013919 & 6.319882 & 1.062782 & 1.501465 & 0 & 0.964802 & 50 \\
1999 & 7.065793071 & 6.368446 & 1.091316 & 1.491611 & 0 & 0.972484 & 50 \\
2000 & 7.178073168 & 6.495293 & 1.144128 & 1.553372 & 0 & 0.971736 & 50 \\
2001 & 7.204530366 & 6.5907 & 1.194434 & 1.556481 & 0 & 0.97888 & 50 \\
2002 & 7.307703986 & 6.819898 & 1.291859 & 1.623498 & 0 & 0.973041 & 50 \\
2003 & 7.512767683 & 6.629342 & 1.216072 & 1.726427 & 0 & 0.982401 & 50 \\
2004 & 7.642242656 & 6.529096 & 1.169525 & 1.80764 & 0 & 0.98078 & 50 \\
2005 & 7.664255062 & 6.680332 & 1.24633 & 1.80788 & 0 & 0.988028 & 50 \\
2006 & 7.795529888 & 6.782577 & 1.295054 & 1.888589 & 0 & 0.988819 & 50 \\
2007 & 7.908674266 & 6.94778 & 1.375558 & 1.961033 & 0 & 0.989214 & 50 \\
2008 & 7.849194645 & 7.110169 & 1.458709 & 1.920989 & 0 & 0.989873 & 50 \\
\hline
\end{tabular}

Source: Author's calculations

The Reaction Function is as follows.

$$
N R a=R a+\left(\frac{R t(1-\delta)}{(1+Z)^{2}}\right) \text { and } N R b=R b+\frac{Z^{2} R t(1-\delta)}{(1+Z)^{2}}
$$

\section{Source: Anderson \& Carter, 2009}

- $\mathrm{NRa}$ and $\mathrm{NRb}$ is the net holdings of the water resource controlled by the 'environmentalist' ( $\mathrm{NRa}$ ) and the local 'electricity producer' ( $\mathrm{NRb}$ ) respectively after the 'environmentalist' and the 'electricity producer' have conflicted over the water resource.

- $\boldsymbol{\delta}$ defines the proportion of loss of resources due to the conflict. As the conflict does not generate loss, or in other words, as water is not destroyed in the conflict process between the parties, it would be safe to assume that $\boldsymbol{\delta}$ is equal to zero.

- $Z$ is the relative effectiveness of B's strategic effort. This is shown by the amount of electricity produced from coal as a percentage of the total energy produced within the country. This is then indexed using 1985 as base year. The effectiveness of the energy producer is determined by using the production of electricity through coal-based power stations as a percentage of the total energy produced. This then could be used as a proxy to reflect the policy used by the 'energy producer'. Source: Index data derived from data provided by the World Bank

- Ra represents the resource holdings of the 'environmentalist'.

- $\mathrm{Rb}$ represents the resource holdings of the 'energy producer'.

- Rt defines the total water resource stock: total renewable fresh water, for South Africa (actual) $\left(10^{9} \mathrm{~m}^{3} / \mathrm{yr}\right)$ (aqua stat), and remains a constant value during the course of this analysis. 
TABLE 5, 6, 7 and 8 apply the data used in the analysis of the reaction function

\begin{tabular}{|c|c|c|c|c|c|c|c|}
\hline & $N R a$ & $N R b$ & $R a$ & $R b$ & $\boldsymbol{\delta}$ & $Z$ & $R t$ \\
\hline 1985 & 3.677343 & 2.711546 & 2.427343 & 2.572657 & 0 & 1 & 5 \\
\hline 1986 & 3.70519181 & 2.714328 & 2.416228 & 2.583772 & 0 & 0.969539 & 5 \\
\hline 1987 & 3.550020829 & 2.848787 & 2.287313 & 2.712687 & 0 & 0.989911 & 5 \\
\hline 1988 & 3.59346247 & 2.843712 & 2.282392 & 2.717608 & 0 & 0.952864 & 5 \\
\hline 1989 & 3.487394078 & 2.947455 & 2.179222 & 2.820778 & 0 & 0.955026 & 5 \\
\hline 1990 & 3.307070432 & 3.097197 & 2.037406 & 2.962594 & 0 & 0.984452 & 5 \\
\hline 1991 & 3.294986879 & 3.118723 & 2.013352 & 2.986648 & 0 & 0.975163 & 5 \\
\hline 1992 & 3.301416575 & 3.106133 & 2.027583 & 2.972417 & 0 & 0.981202 & 5 \\
\hline 1993 & 3.09968185 & 3.289632 & 1.849135 & 3.150865 & 0 & 0.999563 & 5 \\
\hline 1994 & 3.047310948 & 3.361108 & 1.772375 & 3.227625 & 0 & 0.980345 & 5 \\
\hline 1995 & 2.968579651 & 3.444509 & 1.68773 & 3.31227 & 0 & 0.975768 & 5 \\
\hline 1996 & 2.740928474 & 3.672617 & 1.459502 & 3.540498 & 0 & 0.975323 & 5 \\
\hline 1997 & 2.624882419 & 3.794828 & 1.335679 & 3.664321 & 0 & 0.969356 & 5 \\
\hline 1998 & 2.732173913 & 3.692297 & 1.436987 & 3.563013 & 0 & 0.964802 & 5 \\
\hline 1999 & 2.738539953 & 3.677929 & 1.453422 & 3.546578 & 0 & 0.972484 & 5 \\
\hline 2000 & 2.611132425 & 3.80611 & 1.325039 & 3.674961 & 0 & 0.971736 & 5 \\
\hline 2001 & 2.568860057 & 3.841048 & 1.292036 & 3.707964 & 0 & 0.97888 & 5 \\
\hline 2002 & 2.465259975 & 3.950634 & 1.180867 & 3.819133 & 0 & 0.973041 & 5 \\
\hline 2003 & 2.138499934 & 4.267835 & 0.866208 & 4.133792 & 0 & 0.982401 & 5 \\
\hline 2004 & 1.974580695 & 4.433396 & 0.700205 & 4.299795 & 0 & 0.98078 & 5 \\
\hline 2005 & 1.913379035 & 4.487305 & 0.648278 & 4.351722 & 0 & 0.988028 & 5 \\
\hline 2006 & 1.750587743 & 4.649307 & 0.486493 & 4.513507 & 0 & 0.988819 & 5 \\
\hline 2007 & 1.574601952 & 4.8249 & 0.311009 & 4.688991 & 0 & 0.989214 & 5 \\
\hline 2008 & 1.407062562 & 4.991783 & 0.144306 & 4.855694 & 0 & 0.989873 & 5 \\
\hline
\end{tabular}


TABLE 5: Data used for South Africa to examine the reaction function between the 'environmentalist' and the 'energy producer'

\begin{tabular}{|c|c|c|c|c|c|c|c|c|}
\hline & Me & $N R a$ & $N R b$ & $R a$ & $R b$ & sig & $Z$ & $R t$ \\
\hline 1985 & 1.25 & 3.677343 & 2.711546 & 2.427343 & 2.572657 & 0 & 1 & 5 \\
\hline 1986 & 1.249701 & 3.70519181 & 2.714328 & 2.416228 & 2.583772 & 0 & 0.969539 & 5 \\
\hline 1987 & 1.249968 & 3.550020829 & 2.848787 & 2.287313 & 2.712687 & 0 & 0.989911 & 5 \\
\hline 1988 & 1.249272 & 3.59346247 & 2.843712 & 2.282392 & 2.717608 & 0 & 0.952864 & 5 \\
\hline 1989 & 1.249339 & 3.487394078 & 2.947455 & 2.179222 & 2.820778 & 0 & 0.955026 & 5 \\
\hline 1990 & 1.249923 & 3.307070432 & 3.097197 & 2.037406 & 2.962594 & 0 & 0.984452 & 5 \\
\hline 1991 & 1.249802 & 3.294986879 & 3.118723 & 2.013352 & 2.986648 & 0 & 0.975163 & 5 \\
\hline 1992 & 1.249887 & 3.301416575 & 3.106133 & 2.027583 & 2.972417 & 0 & 0.981202 & 5 \\
\hline 1993 & 1.25 & 3.09968185 & 3.289632 & 1.849135 & 3.150865 & 0 & 0.999563 & 5 \\
\hline 1994 & 1.249877 & 3.047310948 & 3.361108 & 1.772375 & 3.227625 & 0 & 0.980345 & 5 \\
\hline 1995 & 1.249812 & 2.968579651 & 3.444509 & 1.68773 & 3.31227 & 0 & 0.975768 & 5 \\
\hline 1996 & 1.249805 & 2.740928474 & 3.672617 & 1.459502 & 3.540498 & 0 & 0.975323 & 5 \\
\hline 1997 & 1.111111 & 3.557901222 & 3.699043 & 1.335679 & 3.664321 & 0 & 0.5 & 5 \\
\hline 1998 & 1.111111 & 3.659209222 & 3.597735 & 1.436987 & 3.563013 & 0 & 0.5 & 5 \\
\hline 1999 & 1.111111 & 3.6756442222 & 3.5813 & 1.453422 & 3.546578 & 0 & 0.5 & 5 \\
\hline 2000 & 1.111111 & 3.547261222 & 3.709683 & 1.325039 & 3.674961 & 0 & 0.5 & 5 \\
\hline 2001 & 1.111111 & 3.514258222 & 3.742686 & 1.292036 & 3.707964 & 0 & 0.5 & 5 \\
\hline 2002 & 1.111111 & 3.403089222 & 3.853855 & 1.180867 & 3.819133 & 0 & 0.5 & 5 \\
\hline 2003 & 1.111111 & 3.088430222 & 4.168514 & 0.866208 & 4.133792 & 0 & 0.5 & 5 \\
\hline 2004 & 1.111111 & 2.922427222 & 4.334517 & 0.700205 & 4.299795 & 0 & 0.5 & 5 \\
\hline 2005 & 1.111111 & 2.870500222 & 4.386444 & 0.648278 & 4.351722 & 0 & 0.5 & 5 \\
\hline 2006 & 1.111111 & 2.708715222 & 4.548229 & 0.486493 & 4.513507 & 0 & 0.5 & 5 \\
\hline 2007 & 1.111111 & 2.533231222 & 4.723713 & 0.311009 & 4.688991 & 0 & 0.5 & 5 \\
\hline 2008 & 1.111111 & 2.366528692 & 4.890416 & 0.144306 & 4.855694 & 0 & 0.5 & 5 \\
\hline
\end{tabular}

Source: Author's calculations 
TABLE 6: Data used for South Africa to simulate the reaction function between the 'environmentalist' and the 'energy producer', when an alternative energy is introduced in 1997

\begin{tabular}{|c|c|c|c|c|c|c|c|}
\hline & $N R a$ & $N R b$ & $R a$ & $R b$ & sig & $Z$ & $R t$ \\
\hline 1985 & 3.677343 & 2.711546 & 2.427343 & 2.572657 & 0 & 1 & 5 \\
\hline 1986 & 3.70519181 & 2.714328 & 2.416228 & 2.583772 & 0 & 0.969539 & 5 \\
\hline 1987 & 3.550020829 & 2.848787 & 2.287313 & 2.712687 & 0 & 0.989911 & 5 \\
\hline 1988 & 3.59346247 & 2.843712 & 2.282392 & 2.717608 & 0 & 0.952864 & 5 \\
\hline 1989 & 3.487394078 & 2.947455 & 2.179222 & 2.820778 & 0 & 0.955026 & 5 \\
\hline 1990 & 3.307070432 & 3.097197 & 2.037406 & 2.962594 & 0 & 0.984452 & 5 \\
\hline 1991 & 3.294986879 & 3.118723 & 2.013352 & 2.986648 & 0 & 0.975163 & 5 \\
\hline 1992 & 3.301416575 & 3.106133 & 2.027583 & 2.972417 & 0 & 0.981202 & 5 \\
\hline 1993 & 3.09968185 & 3.289632 & 1.849135 & 3.150865 & 0 & 0.999563 & 5 \\
\hline 1994 & 3.047310948 & 3.361108 & 1.772375 & 3.227625 & 0 & 0.980345 & 5 \\
\hline 1995 & 2.968579651 & 3.444509 & 1.68773 & 3.31227 & 0 & 0.975768 & 5 \\
\hline 1996 & 2.740928474 & 3.672617 & 1.459502 & 3.540498 & 0 & 0.975323 & 5 \\
\hline 1997 & 3.882723103 & 3.77938 & 2.335679 & 3.664321 & 0 & 0.969356 & 6 \\
\hline 1998 & 3.991211295 & 3.676994 & 2.436987 & 3.563013 & 0 & 0.964802 & 6 \\
\hline 1999 & 3.995563543 & 3.662381 & 2.453422 & 3.546578 & 0 & 0.972484 & 6 \\
\hline 2000 & 3.86835111 & 3.790586 & 2.325039 & 3.674961 & 0 & 0.971736 & 6 \\
\hline 2001 & 3.824224868 & 3.825295 & 2.292036 & 3.707964 & 0 & 0.97888 & 6 \\
\hline 2002 & 3.72213857 & 3.935069 & 2.180867 & 3.819133 & 0 & 0.973041 & 6 \\
\hline 2003 & 3.392958321 & 4.251969 & 1.866208 & 4.133792 & 0 & 0.982401 & 6 \\
\hline 2004 & 3.229455834 & 4.417582 & 1.700205 & 4.299795 & 0 & 0.98078 & 6 \\
\hline 2005 & 3.166399242 & 4.471257 & 1.648278 & 4.351722 & 0 & 0.988028 & 6 \\
\hline 2006 & 3.003406691 & 4.633233 & 1.486493 & 4.513507 & 0 & 0.988819 & 6 \\
\hline 2007 & 2.827320542 & 4.808813 & 1.311009 & 4.688991 & 0 & 0.989214 & 6 \\
\hline 2008 & 2.65961378 & 4.975675 & 1.144306 & 4.855694 & 0 & 0.989873 & 6 \\
\hline
\end{tabular}

Source: Author's calculations 
TABLE 7: Data used for South Africa to simulate the reaction function between the 'environmentalist' and the 'energy producer', when the rainfall increases in 1997

\begin{tabular}{|c|c|c|c|c|c|c|c|}
\hline & $N R a$ & $N R b$ & $R a$ & $R b$ & sig & $Z$ & $R t$ \\
\hline 1985 & 3.677343 & 2.711546 & 2.427343 & 2.572657 & 0 & 1 & 5 \\
\hline 1986 & 3.70519181 & 2.714328 & 2.416228 & 2.583772 & 0 & 0.969539 & 5 \\
\hline 1987 & 3.550020829 & 2.848787 & 2.287313 & 2.712687 & 0 & 0.989911 & 5 \\
\hline 1988 & 3.59346247 & 2.843712 & 2.282392 & 2.717608 & 0 & 0.952864 & 5 \\
\hline 1989 & 3.487394078 & 2.947455 & 2.179222 & 2.820778 & 0 & 0.955026 & 5 \\
\hline 1990 & 3.307070432 & 3.097197 & 2.037406 & 2.962594 & 0 & 0.984452 & 5 \\
\hline 1991 & 3.294986879 & 3.118723 & 2.013352 & 2.986648 & 0 & 0.975163 & 5 \\
\hline 1992 & 3.301416575 & 3.106133 & 2.027583 & 2.972417 & 0 & 0.981202 & 5 \\
\hline 1993 & 3.09968185 & 3.289632 & 1.849135 & 3.150865 & 0 & 0.999563 & 5 \\
\hline 1994 & 3.047310948 & 3.361108 & 1.772375 & 3.227625 & 0 & 0.980345 & 5 \\
\hline 1995 & 2.968579651 & 3.444509 & 1.68773 & 3.31227 & 0 & 0.975768 & 5 \\
\hline 1996 & 2.740928474 & 3.672617 & 1.459502 & 3.540498 & 0 & 0.975323 & 5 \\
\hline 1997 & 5.002345667 & 3.694933 & 2.335679 & 3.664321 & 0 & 0.5 & 6 \\
\hline 1998 & 5.103653667 & 3.593625 & 2.436987 & 3.563013 & 0 & 0.5 & 6 \\
\hline 1999 & 5.120088667 & 3.57719 & 2.453422 & 3.546578 & 0 & 0.5 & 6 \\
\hline 2000 & 4.991705667 & 3.705573 & 2.325039 & 3.674961 & 0 & 0.5 & 6 \\
\hline 2001 & 4.958702667 & 3.738576 & 2.292036 & 3.707964 & 0 & 0.5 & 6 \\
\hline 2002 & 4.847533667 & 3.849745 & 2.180867 & 3.819133 & 0 & 0.5 & 6 \\
\hline 2003 & 4.532874667 & 4.164404 & 1.866208 & 4.133792 & 0 & 0.5 & 6 \\
\hline 2004 & 4.366871667 & 4.330407 & 1.700205 & 4.299795 & 0 & 0.5 & 6 \\
\hline 2005 & 4.314944667 & 4.382334 & 1.648278 & 4.351722 & 0 & 0.5 & 6 \\
\hline 2006 & 4.153159667 & 4.544119 & 1.486493 & 4.513507 & 0 & 0.5 & 6 \\
\hline 2007 & 3.977675667 & 4.719603 & 1.311009 & 4.688991 & 0 & 0.5 & 6 \\
\hline 2008 & 3.810973137 & 4.886306 & 1.144306 & 4.855694 & 0 & 0.5 & 6 \\
\hline
\end{tabular}


Baur

TABLE 8: Data used for South Africa to simulate the reaction function between the 'environmentalist' and the 'energy producer', when the rainfall increases and the 'energy producer' forces a policy shift in 1997

\begin{tabular}{|c|c|c|c|c|c|c|c|c|}
\hline & $M$ & $M a^{*}$ & $M b^{*}$ & Ma & Mb & sig & $z$ & $R t$ \\
\hline 2010 & 1.25 & 1.236068 & 1.236067977 & 1 & 1 & 0 & 1 & 5 \\
\hline 2011 & 1.249538 & 1.242408 & 1.227718578 & 0.975309 & 1.022656 & 0 & 1.039216 & 5 \\
\hline 2012 & 1.249474 & 1.24513 & 1.223054277 & 0.948 & 1.054654 & 0 & 1.041882 & 5 \\
\hline 2013 & 1.249652 & 1.24795 & 1.223008416 & 0.940476 & 1.113057 & 0 & 1.033916 & 5 \\
\hline 2014 & 1.24993 & 1.249208 & 1.225819887 & 0.940476 & 1.170158 & 0 & 1.015115 & 5 \\
\hline 2015 & 1.249749 & 1.249015 & 1.228160132 & 0.915058 & 1.214797 & 0 & 0.972032 & 5 \\
\hline 2016 & 1.249714 & 1.249643 & 1.225631469 & 0.897727 & 1.245223 & 0 & 0.970192 & 5 \\
\hline 2017 & 1.249913 & 1.249784 & 1.218749602 & 0.871324 & 1.304637 & 0 & 0.983476 & 5 \\
\hline 2018 & 1.249924 & 1.245767 & 1.2038687 & 0.828671 & 1.378085 & 0 & 1.015698 & 5 \\
\hline 2019 & 1.249732 & 1.23904 & 1.193490073 & 0.79798 & 1.451914 & 0 & 1.02971 & 5 \\
\hline 2020 & 1.248542 & 1.225468 & 1.178425304 & 0.77451 & 1.517436 & 0 & 1.070727 & 5 \\
\hline 2021 & 1.247448 & 1.212303 & 1.168010382 & 0.757188 & 1.572965 & 0 & 1.09465 & 5 \\
\hline 2022 & 1.248626 & 1.214332 & 1.1692235 & 0.742947 & 1.598338 & 0 & 1.06859 & 5 \\
\hline 2023 & 1.249969 & 1.230111 & 1.183870014 & 0.733746 & 1.601145 & 0 & 0.990066 & 5 \\
\hline 2024 & 1.249356 & 1.232882 & 1.186937103 & 0.718182 & 1.63211 & 0 & 0.955621 & 5 \\
\hline 2025 & 1.246108 & 1.240045 & 1.19652281 & 0.703264 & 1.658336 & 0 & 0.894302 & 5 \\
\hline 2026 & 1.246681 & 1.235585 & 1.187944304 & 0.681034 & 1.699427 & 0 & 0.901998 & 5 \\
\hline 2027 & 1.24721 & 1.229423 & 1.179141658 & 0.660167 & 1.749141 & 0 & 0.909779 & 5 \\
\hline 2028 & 1.238615 & 1.240991 & 1.196508231 & 0.649315 & 1.7817 & 0 & 0.825756 & 5 \\
\hline 2029 & 1.233028 & 1.243714 & 1.201278251 & 0.637097 & 1.811721 & 0 & 0.791273 & 5 \\
\hline 2030 & 1.233307 & 1.242316 & 1.196056297 & 0.622047 & 1.833569 & 0 & 0.792821 & 5 \\
\hline
\end{tabular}

Source: Author's calculations 
TABLE 9: Data used for South Africa to simulate the reaction function between the 'environmentalist' and the 'energy producer', as proposed by the IRP 2010-2030, base case scenario, using 2010 as the base year

\begin{tabular}{|c|c|c|c|c|c|c|c|}
\hline & $N R a$ & $N R b$ & $R a$ & $R b$ & sig & $Z$ & Rt \\
\hline 2010 & 2.8858 & 3.503089 & 1.6358 & 3.3642 & 0 & 1 & 5 \\
\hline 2011 & 2.722815313 & 3.64214 & 1.50387 & 3.49613 & 0 & 1.025316 & 5 \\
\hline 2012 & 2.679055602 & 3.659644 & 1.4949 & 3.5051 & 0 & 1.054852 & 5 \\
\hline 2013 & 2.696189066 & 3.635326 & 1.5217 & 3.4783 & 0 & 1.063291 & 5 \\
\hline 2014 & 2.759439066 & 3.572076 & 1.58495 & 3.41505 & 0 & 1.063291 & 5 \\
\hline 2015 & 2.871462093 & 3.435981 & 1.72989 & 3.27011 & 0 & 1.092827 & 5 \\
\hline 2016 & 2.854979925 & 3.436257 & 1.73608 & 3.26392 & 0 & 1.113924 & 5 \\
\hline 2017 & 2.775394616 & 3.49155 & 1.69139 & 3.30861 & 0 & 1.147679 & 5 \\
\hline 2018 & 2.609736707 & 3.619267 & 1.58299 & 3.41701 & 0 & 1.206751 & 5 \\
\hline 2019 & 2.520731959 & 3.682264 & 1.53585 & 3.46415 & 0 & 1.253165 & 5 \\
\hline 2020 & 2.350364502 & 3.833673 & 1.39786 & 3.60214 & 0 & 1.291139 & 5 \\
\hline 2021 & 2.245793223 & 3.924868 & 1.31738 & 3.68262 & 0 & 1.320675 & 5 \\
\hline 2022 & 2.313533645 & 3.846574 & 1.40505 & 3.59495 & 0 & 1.345992 & 5 \\
\hline 2023 & 2.564771658 & 3.588754 & 1.66922 & 3.33078 & 0 & 1.362869 & 5 \\
\hline 2024 & 2.658675768 & 3.484177 & 1.7851 & 3.2149 & 0 & 1.392405 & 5 \\
\hline 2025 & 2.843788961 & 3.289432 & 1.99139 & 3.00861 & 0 & 1.421941 & 5 \\
\hline 2026 & 2.786144313 & 3.333953 & 1.9655 & 3.0345 & 0 & 1.468354 & 5 \\
\hline 2027 & 2.729951616 & 3.379364 & 1.93932 & 3.06068 & 0 & 1.514768 & 5 \\
\hline 2028 & 2.996940056 & 3.107435 & 2.22199 & 2.77801 & 0 & 1.540084 & 5 \\
\hline 2029 & 3.095237497 & 3.004182 & 2.338 & 2.662 & 0 & 1.56962 & 5 \\
\hline 2030 & 3.068132634 & 3.026149 & 2.33279 & 2.66721 & 0 & 1.607595 & 5 \\
\hline
\end{tabular}

Source: Author's calculations 